\title{
IMPROVEMENT OF THE CITY TRANSPORT SYSTEM BY MEANS OF SIMULATION
}

\author{
Polina A. Buyvol ${ }^{1}$ \\ Gulnara A. Yakupova ${ }^{2}$ \\ Irina V. Makarova ${ }^{3}$
}

\begin{abstract}
The transport system plays an important role in human activities and is an integral part of the successful functioning of the urbanized area. The increasing degree of provision of urban residents with transport services should at the same time keep the environment environmentally friendly and sustainable over time. The article is devoted to the issues of ensuring the rational functioning of the city transport system based on the development and implementation of an intelligent road infrastructure management system, the intellectual core of which are simulation models of problem areas of the road network. The objective of the study is the development of tools for organizing traffic in the conditions of the rapid growth of the fleet of vehicles. Research tasks were to analyze the research in the
\end{abstract} field of traffic management, to consider methods to reduce and prevent traffic jams on roads in general and in individual sections in particular. The following research methods were used: methods of system analysis, methods of modeling traffic flows, simulation, computer experiment. Achievements: the developed simulation model can be used to conduct a computer experiment in order to select the optimal parameters for the functioning of traffic lights on a specific section of the road network of the city of Naberezhnye Chelny.

Keywords: transport system, traffic light regulation, intelligent transport systems, simulation.

\section{Introduction}

\footnotetext{
${ }^{1}$ Kazan Federal University. e-mail: PABujvol@kpfu.ru. Tel.: +7(927) 4508605.

${ }^{2}$ Kazan Federal University. e-mail: PABujvol@kpfu.ru. Tel.: +7(927) 4508605.

${ }^{3}$ Kazan Federal University. e-mail: PABujvol@kpfu.ru. Tel.: +7(927) 4508605.
} 
Within the framework of the concept of sustainable development of the city defined by the United Nations Commission on the Environment and Development back in 1992, it is necessary to make the urban environment more attractive by expanding various types of services, including transport. However, these measures should not be carried out to the detriment of the environmental safety of the environment. At present, one of the main problems associated with road transport both in large cities and in small settlements is traffic jams, the causes of which often differ. First of all, this is the growing car fleet. The positive effect of growing motorization in the form of increasing mobility of the population goes in parallel with the growing traffic intensity on the city's street-road network (SRN). As a result, huge congestion is formed, accompanied by an intensive emission of exhaust gases into the environment and an increase in noise pollution, road safety is reduced, and injuries are growing.

One effective way to reduce traffic congestion is to control traffic. As part of the "sustainable mobility" plan, many cities around the world develop car-free policies (creating car-free zones). For this purpose, various strategies are developed:

- bans on diesel vehicles, introduced simultaneously with the protectionism policy of public and nonmotorized environmentally friendly vehicles;

- the introduction of a pricing system that involves charging for driving a car during peak hours, to certain particularly busy urban areas, or for vehicles that do not meet the minimum environmental emission standards.

- restricted entry of cars with certain license plates: setting a schedule for the possibility of movement in urban areas with even and odd numbers [1].

As a rule, the development of city infrastructure lags behind the growth rate of the fleet. One of the ways to solve this priority task for any city is to build high-quality highways with convenient interchanges and passive and active safety elements.

In addition to infrastructure changes, organizational measures are needed to solve the transport problem. For traffic management, in many countries, intelligent transport systems (ITS) are widely used, which are based 


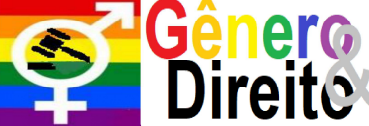

Periódico do Núcleo de Estudos e Pesquisas sobre Gênero e Direito Centro de Ciências Jurídicas - Universidade Federal da Paraíba V. 8 - No 06 - Ano 2019 - Special Edition ISSN | 2179-7137 | http://periodicos.ufpb.br/ojs2/index.php/ged/index on modern computer and telecommunication technologies.

They solve a number of problems:

- optimize urban planning decisions;

- ensure maximum throughput of the existing SRN;

- identify priority directions of traffic;

- optimize parking space and infrastructure;

- reduce the environmental burden [2].

\section{Methods}

There are a number of studies regarding the organization and optimization of traffic on highways. Thus, we can name the technique of Plotnikov A.M. to improve road safety at single-level regulated intersections with a small number of lanes [3]; the methodology for modeling the SRN congestion proposed by Agureev I.E., Pyshnyi V.A. [4]; the methodology for assessing the state of motor flows on city roads developed by A. Kretov, V. Mitiugin, V.A. Pyshnyi, N.A. Frolov [5]. Foreign scientists have also proposed many effective methods for optimizing traffic. They describe specific measures to modernize the SRN, and, in order to exclude traffic jams, they propose methods for studying the flow of road transport, its intensity, and direction [610]. It should be noted that many researchers call the basis for improving road traffic a comprehensive study of the existing UDS [11]. The most effective approach, in their opinion, is to reconstruct the geometry of the existing network (changing the number of lanes, erecting fences and road signs) and optimizing the work of traffic lights based on the study of traffic intensity at a specific object [12-15].

Thus, if it is impossible to reduce the traffic intensity of automobile transport, it is necessary to adopt engineering and organizational measures that will help reduce the time of movement of road users. The search for more rational ways to use the existing SRN capacity involves the creation of ITS [16], which are one of the main tools even when it is impossible to adjust the width of the roadway. In this case, it is possible to improve the transport system by optimizing the operating modes of traffic lights. The development of wireless communication between 
sensors and decision support systems (DSS) made it possible to create intelligent traffic lights that provide for operational adjustment of the phase duration depending on the current traffic intensity. In addition, this measure, aimed at reducing the travel time by car of a specific section of the road, will help to reduce the volume of exhaust gases and, as a result, the environmental burden on this territory.

Since variation of the duration of the phases of a real traffic light and monitoring over subsequent changes in the traffic situation is fraught with risks (material, human, temporary), and many parameters (flow intensity in the first place) are stochastic, the solution in this situation is to build a simulation model of the SRN section and conducting an experiment on it.

\section{Results And Discussion}

As part of the training course "Methods and Models of Decision Support" in "Intelligent Systems and Technologies", students are invited to create a model of the intersection of Chulman Avenue and Narimanova Street, Naberezhnye Chelny, taking as a basis a satellite image of the area, which shows the configuration features of this section of the road network [17]. Both roads are two-way but have a different number of lanes for traffic in each direction. In addition, in Narimanova street there is an exit to a gas station.

The environment for building a simulation model is the AnyLogic $®$ software package. To develop a model, a Road traffic library is used. 
243

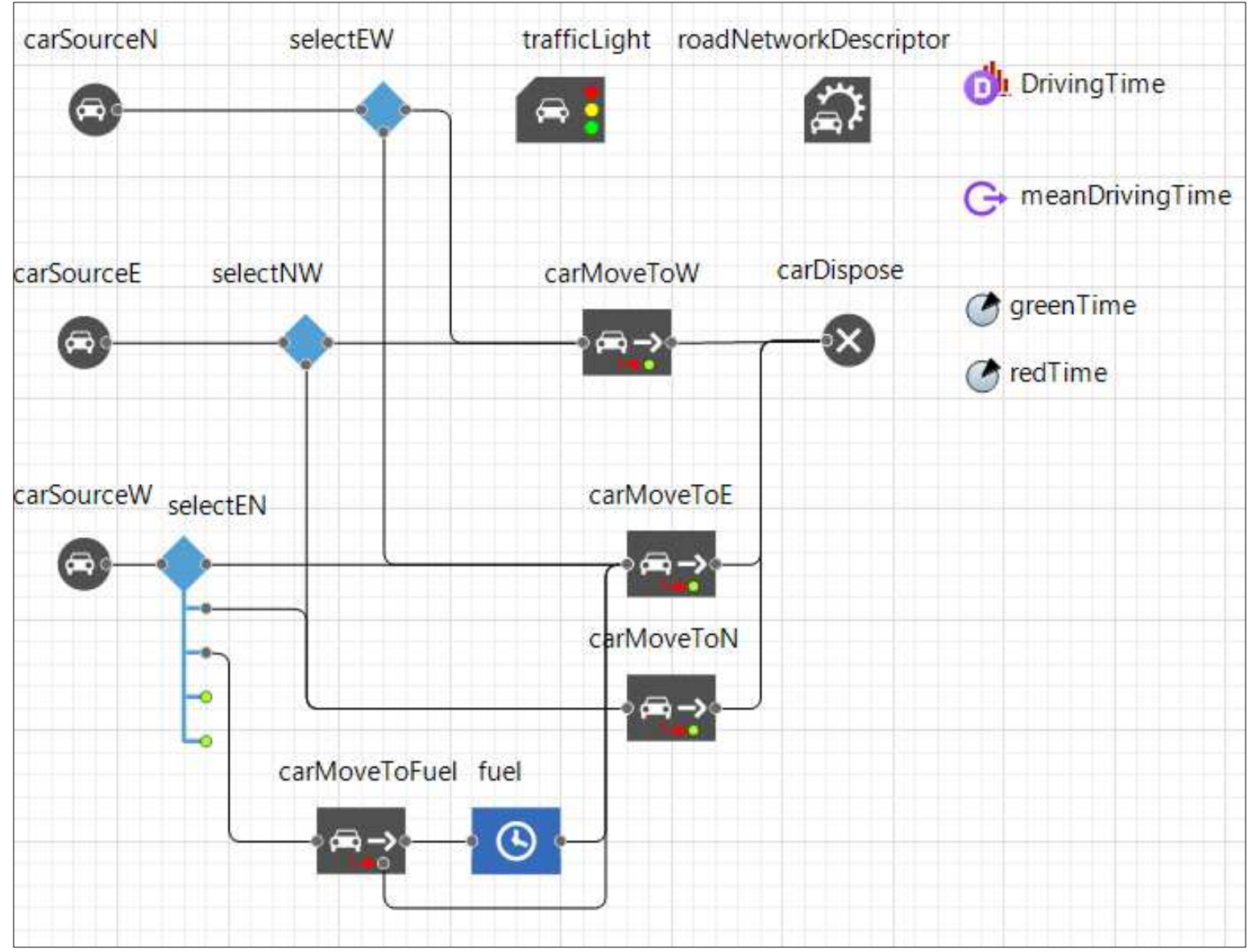

Figure 1 - The structure of the simulation model of the intersection

In addition to setting the geometry of the road section, it is necessary to enter information about the intensity of the traffic flow in each direction of movement, the time of operation of the traffic light phases, the number of channels and the average service time at a fuel station.

The next step is to determine the logic of the traffic light. In this case, the traffic light will operate in a two-phase mode: the first phase will be green for traffic along Narimanova Street in the permitted directions, and the second phase will be green to enter the intersection from Chulman Avenue and turn right from Narimanova Street. When the green light is on to leave the fuel station, drivers moving along this road will have to give way anyway.

AnyLogic provides the user with convenient tools for collecting statistics. The user can view the statistics of the duration of the passage of a given section of the road using the diagram. To better understand the way the roads are 
loaded at a given mode of operation of traffic lights (a section of the road is highlighted in green if the vehicle speed is above $60 \mathrm{~km} / \mathrm{h}$ and red if it is below 10 $\mathrm{km} / \mathrm{h}$ ), it is useful to enable traffic jam display.

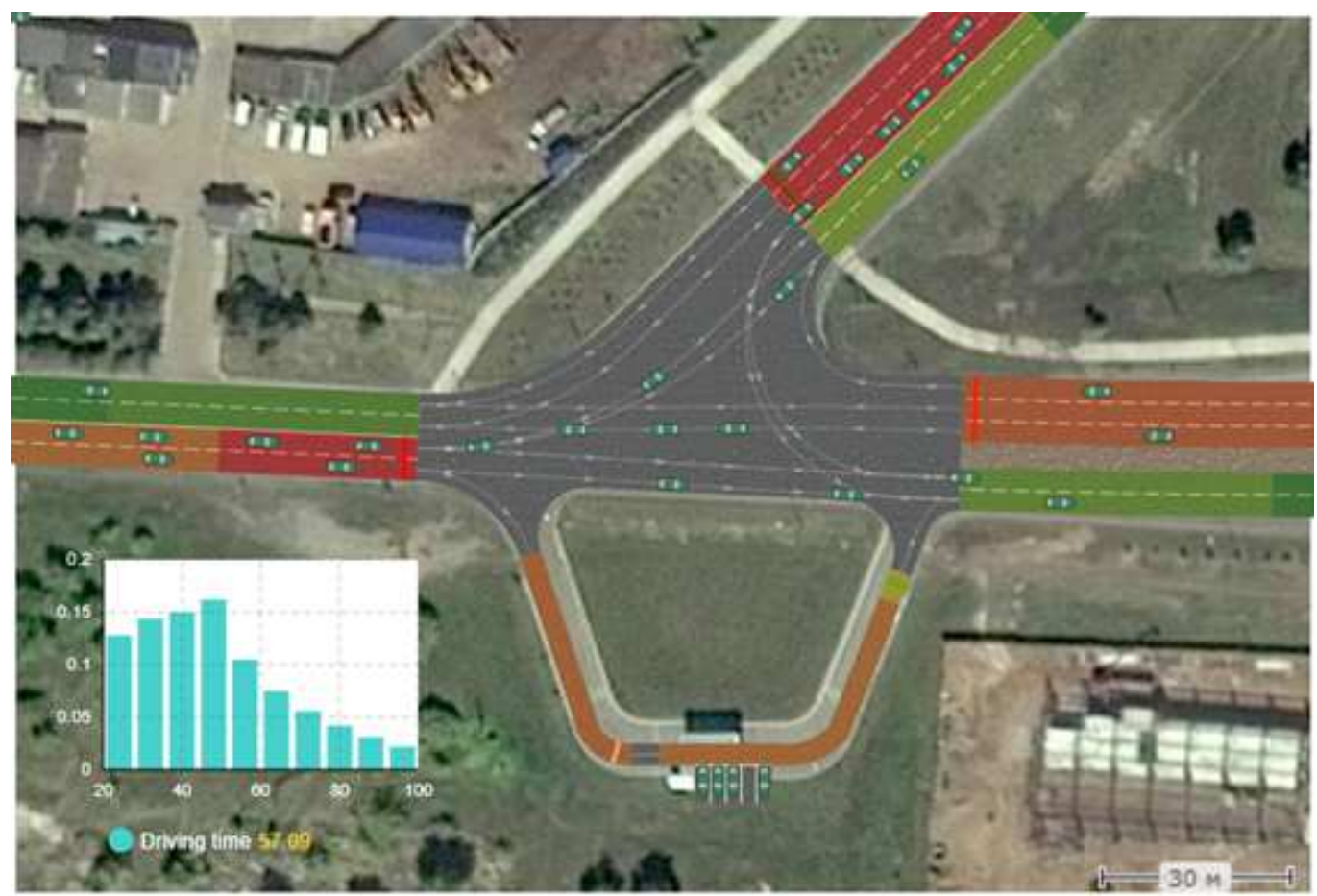

Figure 2 - The results of the test of the intersection model with the current parameters of the traffic lights

The final goal of building any section of the road is to determine the optimal parameters (the number of lanes, the duration of the phases of the traffic light, the permissible traffic intensity) to achieve the minimum or maximum value of a certain functional. Using optimization, in which the selected model parameters are systematically changed, it is possible to achieve a preselected target functional.
In this case, the average travel time of a road section by a vehicle is selected as the objective function, and the operating time of the green and red traffic lights is selected as variable parameters. The task of finding the extremum of the target functional in AnyLogic ${ }^{\circledR}$ is carried out using the OptQuest optimizer, which is a combination of heuristics, neural networks, and mathematical optimization. 
The found values of the parameters can be used in the model as the optimal strategy that ensures the minimum travel time of the vehicle through the intersection.

\section{City : Optimization}

\begin{tabular}{lr|r} 
& Current & Best \\
\hline Iterations completed: & 250 & 56 \\
Objective: $\downarrow$ & 70.176 & 52.661 \\
& & Copy best \\
\hline Parameters & & 25 \\
\hline greenTime & 50 & 22 \\
redTime & 60 &
\end{tabular}

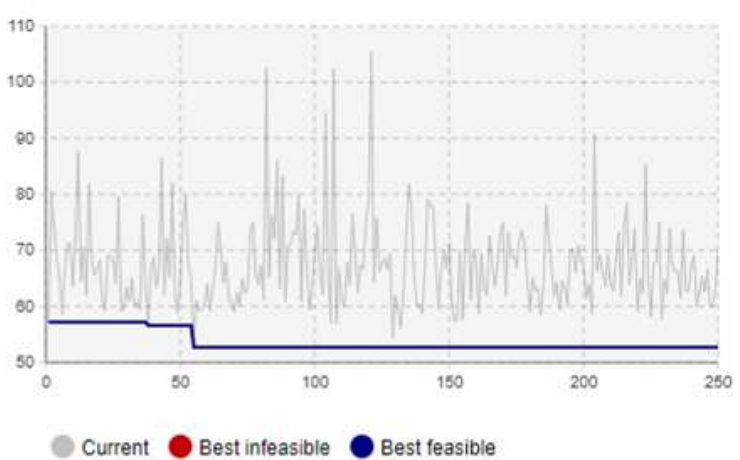

A Finished

\section{Figure 3 - Results of the optimization experiment}

\section{Summary}

In the framework of this work, an example of a simulation model of a SRN section as a means of developing managerial decisions is shown. The practical significance of the model is the possibility of conducting an experiment that will determine the optimal operating time of the traffic light phases, which will reduce congestion in this section of the SRN, the idle time of automobile engines, and thereby reduce the amount of exhaust gas. Thus, based on the data obtained as a result of modeling, it is possible to develop recommendations for the rational management of the transport system of urbanized areas of both a strategic nature (when determining constant traffic light settings) and operational management of 
traffic, changing the duration of the phases depending on the time of day, day of the week, weather and other conditions, embedding the developed simulation model as an intellectual core in DSS to control the transport system of the city.

\section{Conclusions}

The growing number of private and public transport fleets leads to the increasing burden on the existing SRN of city and urban settlements. In connection with the duration of the road reconstruction measures, tools for the operational adjustment of infrastructure facilities, primarily traffic lights, come to the fore. Within the framework of the concept of sustainable development, it is proposed to develop and implement DSS to control the transport system of the city, with simulation models as the intellectual core, with which you can set the optimal duration of the phases of the traffic lights depending on traffic intensity. This will reduce the travel time of road users and, as a result, reduce the environmental burden on the environment.

\section{Acknowledgements}

The work is performed according to the Russian Government Program of Competitive Growth of Kazan Federal University.

\section{References}

What cities refuse cars and why. URL: https://vc.ru/future/46544-kakie-gorodaotkazyvayutsya-ot-mashin-i-zachemeto-nuzhno.

M.KH. GATIIATULLIN, R.R. ZAGIDULLIN, INTELLIGENT SYSTEM FOR LARGE CITIES, VESTNIK SC BZD, NO. 5, P.76 - 85, 2010.

A.M. Plotnikov, Road safety assessment methodology at single-level road intersections, Bulletin of Civil Engineers, No. 6 (71), P.201-207, DOI: 10.23968/1999-5571-2018-15-6-201207, 2018.

I.E. Agureev, V.A. Pyshnyi, V.I. Shvetsov, Modeling the congestion of the road network in the city of Tula, Izvestiya TulSU. Engineering Sciences, is. 6, part 2, P.127-139, 2013. 
A.Iu. Kretov, V.A. Mitiugin, V.A. Pyshnyi, N.A. Frolov, Integrated methodology for assessing the state of traffic flows on the road network, Science and Innovation in Technical Universities. Materials of the Seventh All-Russian Forum of Students, Graduate Students, and Young Scientists, St. Petersburg: Publishing House of the Polytechnic University, P. 41-43, 2013.

A. Lebdeh. G.Rahim, F. Benekohal, "Genetic Algorithmfor Traffic Signal Controland Queue Management of Oversaturated Two- Way Arterials", In Transportation Research Record: Journal of the Transportation Research Board No. 1727, TRB, National Research Council, Washington, DC, pp. 61-67, 2000.

A.T. Hsien, J.T. Lin, "Optimal Signal Timing for an Oversaturated Intersection", Transportation Research, Part B, vol. 34, pp. 471-491, 2000.
J. Rychlewski, "Street network design for a sustainable mobility system", Transportation Research Procedia, vol. 14, pp. 528 - 537, 2016.

S.S. Keshkamat, J.M. Looijen, M.H.P. Zuidgeest, "The formulation and evaluation of transport route planning alternatives: a spatial decision support system for the Via Baltica project, Poland", Journal of Transport Geography, vol.17, pp. 54. 2009. 2018

M. A. Javed, S. Zeadally, E. B. Hamida, "Data analytics for Cooperative Intelligent Transport Systems", Vehicular Communications, vol. 15, pp. 63. 2019. 2018

I. Makarova, K. Shubenkova, V. Mavrin, P. Buyvol, "Improving safety on the crosswalks with the use of fuzzy logic," Transport Problems, vol. 13, iss. 1, pp. 97-109, 2018.

Iu.N. Baranov, A.A. Katunin, R.V. Shkrabak, Iu.N. Braginets, "Fundamentals of security in the "man machine - environment" system", 
Bulletin of the Scientific Center of Belarusian Railways, No. 1 (19), P. 73$76,2014$.

A.N. Novikov, V.A. Golenkov, Iu.N. Baranov, A.A. Katunin, A.S. Bodrov, "Improving the road network to increase their throughput using means of transport telematics", News of TulSU. Engineering Sciences, is. 6. part 2, $\mathrm{P}$. 128-139, 2014.

V. Gorodokin, Z. Almetova, V. Shepelev, "Procedure for calculating ontime duration of the main cycle of a set of coordinated traffic lights", Transportation Research Procedia, № 20, pp. 231-235, 2017.

I. Makarova, G. Yakupova, P. Buyvol, K. Shubenkova, K. Abeshev, M. Drakaki "Improving Road Safety by Affecting Negative Factors", In Proceedings of the 5th International Conference on Vehicle Technology and Intelligent Transport Systems, vol. 1: LogiTrans 4.0, pp. 629637, 2019.

F. Viti, C. Tampere, "Models and Technologies for Intelligent
Transportation Systems: New

Challenges and Metaheuristic Solutions for Large-Scale Network Applications", Journal of Intelligent Transportation Systems: Technology, Planning, and Operations, № 18, pp. 1-4, 2014.

Yandex. National map. URL: https://n.maps.yandex.ru/\#!/?z=19\&ll=5 $2.357277 \% 2 \mathrm{C} 55.718685 \& \mathrm{l}=\mathrm{nk} \% 23$ sat. 